\title{
Article \\ Application of Microgel as a Sorbent for Bisphenol Analysis in Liquid Food Samples
}

\author{
Anna Kubiak (D), Marcin Maćkiewicz, Marcin Karbarz (D) and Magdalena Biesaga *(D)
}

Citation: Kubiak, A.; Maćkiewicz, M.; Karbarz, M.; Biesaga, M. Application of Microgel as a Sorbent for Bisphenol Analysis in Liquid Food Samples. Appl. Sci. 2022, 12, 441. https:// doi.org/10.3390/app12010441

Academic Editor: Claudio Medana

Received: 8 December 2021

Accepted: 30 December 2021

Published: 3 January 2022

Publisher's Note: MDPI stays neutral with regard to jurisdictional claims in published maps and institutional affiliations.

Copyright: () 2022 by the authors Licensee MDPI, Basel, Switzerland. This article is an open access article distributed under the terms and conditions of the Creative Commons Attribution (CC BY) license (https:// creativecommons.org/licenses/by/ $4.0 /)$.
Faculty of Chemistry, University of Warsaw, Pasteur 1 St., 02-093 Warsaw, Poland; akubiak@chem.uw.edu.pl (A.K.); mmackiewicz@chem.uw.edu.pl (M.M.); karbarz@chem.uw.edu.pl (M.K.) * Correspondence: mbiesaga@chem.uw.edu.pl; Tel.: +48-55-26-328

Featured Application: The synthesized microgels can become a cost-effective sorbent for the removal of bisphenols from an aqueous medium.

\begin{abstract}
Bisphenols are well-known endocrine disruptors that can easily migrate from plastic and can containers to food. Due to the complicated matrix and ultra-low concentrations of bisphenols in food, samples require extensive preparation before instrumental analysis. In this paper, an environmental sensitive microgel was employed as a sorbent for the preconcentration of four bisphenols, bisphenol A (BPA), bisphenol B (BPB), bisphenol E (BPE) and bisphenol F (BPF), from liquid food samples. Liquid chromatography with fluorescence detection (LC-FLD) was used for the quantification of bisphenols. By applying microgel solid-phase extraction procedure, the limits of detections achieved in liquid food samples can be lowered to $0.9 \mu \mathrm{g} \cdot \mathrm{L}^{-1}$ for BPF and BPA, $2.3 \mu \mathrm{g} \cdot \mathrm{L}^{-1}$ for BPE and $2.9 \mu \mathrm{g} \cdot \mathrm{L}^{-1}$ for BPB. Only $5 \mathrm{mg}$ of microgel was sufficient to achieve good recoveries $(70.5-109 \%)$ with precision (RSD $0.21-5.01 \%, n=3$ ) for different analyzed liquid food samples spiked at concentration levels of $50 \mu \mathrm{g} \cdot \mathrm{L}^{-1}$. In five out of twelve of the analyzed samples (pineapple, mandarin, peach, mushroom and pickles), they were contaminated with BPA, and the determined concentration was in the range of $6.2-22 \mu \mathrm{g} \cdot \mathrm{L}^{-1}$; however, these results are below the specific migration limit (SML) set for BPA $\left(50 \mu \mathrm{g} \cdot \mathrm{kg}^{-1}\right)$.
\end{abstract}

Keywords: microgel; bisphenols; solid-phase extraction; chromatography; food samples

\section{Introduction}

Food contamination might be one of the most common methods of hazardous substances being ingested into a human body. One of the sources of food contamination is inadequate packaging, which may result in the migration of chemical compounds [1]. Among these substances are bisphenols, which are often employed in the production of polycarbonate and epoxy resins. These materials are often used to manufacture plastic bottles, internal coating of cans, food containers and microwave oven dishes [2]. BPA release from polycarbonate is explained by two different processes: diffusion-controlled release of residual BPA present in the polymer and hydrolysis, decomposition overtime at the polymer's surface [3]. Special attention should be also paid to plastics marked with recycling codes 3 (polyvinyl chloride) or 7 (other types), as they might be made with BPA or its analogue [4]. Bisphenols are becoming well known as they appear to be aggressive endocrine disruptors, and they can easily migrate from plastic and can containers to food [5]. Endocrine disrupting compounds (EDC) disrupt proper functioning of endogenous hormones by mimicking their actions, which results in interferences with synthesis, transport and metabolism of steroid hormones [6]. Bisphenol A is linked to a variety of reproductive and cardiovascular diseases $[4,7,8]$ and the development of many types of cancer (including lung, breast and prostate cancer) $[9,10]$. For this reason, since January 2011, the manufacture of baby bottles containing BPA is prohibited in European Union, 
while, since September 2018, the specific migration limit from plastic packaging for BPA was reduced to $50 \mu \mathrm{g} \cdot \mathrm{kg}^{-1}$ [11]. These restrictions regarding the use of BPA in plastic containers result in the replacement of BPA with its alternatives. Unfortunately, many of them are also bisphenols with estrogenic activity (BPB, BPS, BPE and BPF) [12-14]. As it has also been stated in a review article written by Chen et al. [15], although the estimated daily intake rates of bisphenols might be low, the potential additive or synergistic effects produced by a mixture of bisphenol analogues may be dangerous to human health and should be considered in epidemiological studies assessments. Due to these facts, when evaluating the safety of compounds for consumer use, it is essential to consider entire classes instead of individual compounds [16].

Several reviews carefully described analytical methods and sample preparation used for the determination of bisphenols in food [17-20]. Chromatographic methods such as gas chromatography (GC) or high-performance liquid chromatography (LC) with mass spectrometry are the most often used for the determination of bisphenols. However, due to the complicated matrix and ultra-low concentrations of bisphenols in food [11], samples often require extensive preparation before instrumental analysis. The majority of preconcentration methods used for the extraction of bisphenols from food are based on solidphase extraction (SPE) $[18,21]$ or microextraction techniques [22,23], where molecularly imprinted polymers (MIP) were often used as selective sorbents.

One of the novel alternatives of cost-effective sorbent are microgels [24], as their porous structure provides advantages, such as strong mechanical strength and large specific surface area, which can uptake a high concentration of the analyte [25]. As was stated by Naseem et al. [26], a major attribution of the usage of microgels is their ability to regenerate and be reused for several cycles. Recently, a few papers presented microgels, which were dedicated as a sorbent for BPA extraction. Du et al. [27] synthesized a polyethylene glycol diacrylate (PEGDA) hydrogel microsphere via reverse emulsion/UV light polymerization and applied it for the enrichment of BPA in spiked water samples. By applying $10 \mathrm{mg}$ of hydrogel for spiked river samples, they achieved $91 \%$ recovery, which confirmed the application of hydrogel in real samples [27]. A powdered and activated carbon embedded chitosan-polyvinyl alcohol composite (PAC/CS/PVA) hydrogel was presented by Zhou et al. [24]. They fabricated both hydrophobic/hydrophilic bifunctional sorbents for the removal of sulfamethoxazole and bisphenol A from water. The adsorption performance of PAC/CS/PVA hydrogel was investigated under different typical water matrices, which resulted in the conclusion that ions, such as $\mathrm{Cu}^{2+}, \mathrm{Cl}^{-}$and $\mathrm{SO}_{4}{ }^{2-}$, had an insignificant effect on the adsorption of bisphenol. Unfortunately, until now, no paper presented the application of microgel for bisphenols sorption in complex food samples.

In a previous article [28], we described the synthesis and characterization of environmental sensitive microgel, which showed very good sorption for bisphenols. Therefore, this paper investigates the application of the microgel as a novel sorbent for the preconcentration of four common bisphenols (Figure 1). The extraction procedure was optimized and used on food samples, which might be exposed to bisphenol contamination due to the package in which they were stored. To the best of our knowledge, it is the first report about the application of microgels as sorbents for bisphenols preconcentration in complex samples. Various factors affecting adsorption and desorption steps for the preconcentration of BPF, BPE, BPA and BPB were investigated and optimized. Finally, the developed procedure was employed to determine these analytes in different liquid food samples. 


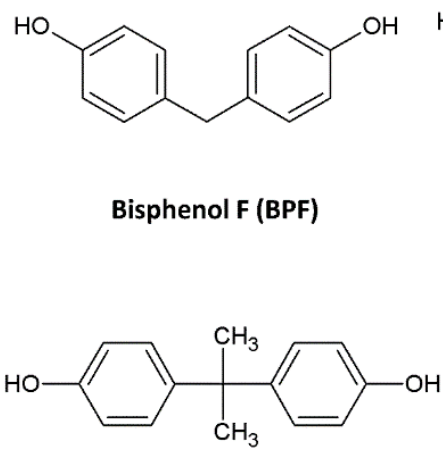

Bisphenol A (BPA)<smiles>CC(c1ccc(O)cc1)c1ccc(O)cc1</smiles>

Bisphenol E (BPE)

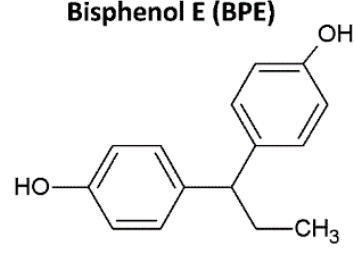

Bisphenol B (BPB)

Figure 1. Structures of the analyzed bisphenols.

\section{Materials and Methods}

\subsection{Reagents}

Solvents and standards used were of analytical grade. Methanol and acetonitrile were from Merck (Darmstadt, Germany, https: / / www.merckgroup.com/en). Bisphenol A (BPA, 99\% analytical purity), bisphenol $\mathrm{F}$ (BPF, 99.7\% analytical purity), bisphenol E (BPE, 98\% analytical purity) and bisphenol B (BPB, 98\% analytical purity) were purchased from SigmaAldrich (Steinheim, Germany, https: / www.sigmaaldrich.com). Di(ethylene glycol) methyl ether methacrylate $\left(\mathrm{MEO}_{2} \mathrm{MA}\right)$, ethylene dimethacrylate (EGDMA), oligo(ethylene glycol) methyl ether methacrylate (OEGMA), acrylic acid (AA) and ammonium persulfate (APS) were obtained from Sigma-Aldrich (Steinheim, Germany, https: / www.sigmaaldrich.com). Supelclean $^{\mathrm{TM}}$ ENVI-18 SPE cartridges were purchased from Sigma-Aldrich (Steinheim, Germany, https:/ / www.sigmaaldrich.com), and Affinimip ${ }^{\circledR}$ cartridges were purchased from Affinisep (Petit-Couronne, France, https://www.affinisep.com/). Water was purified by using a Milli-Q Plus system from Merck Millipore (Millipore, Bedford, MA, USA, http: //www.millipore.com/). Sample workup and preparation were exclusively performed with gloves and bisphenol-free laboratory ware. Stock solutions of standards were prepared at a concentration of $1 \mathrm{~g} \cdot \mathrm{L}^{-1}$ in water/methanol $(90: 10,10 \mathrm{~mL})$ and were stored in the refrigerator until use. Working solutions for calibration were developed as a standard mix by dilution of the stock solutions with water and were used immediately before analysis.

\subsection{Synthesis of Microgel}

The microgel was synthesized by precipitation polymerization and it consisted of the main monomer $\mathrm{MEO}_{2} \mathrm{MA}$, two co-monomers OEGMA and AA and EGDMA was used as a linker. All ingredients were dissolved in $60 \mathrm{~mL}$ of deionized water. The total concentration of monomers in the reaction mixture was set to $70 \mathrm{mM}\left(81 \mathrm{~mol} \%\right.$ of $\mathrm{MEO}_{2} \mathrm{MA}, 10 \mathrm{~mol} \%$ of OEGMA, $7 \mathrm{~mol} \%$ of AA and $2 \mathrm{~mol} \%$ of EGDMA), and $17 \mathrm{mg}$ of APS was added later to the solution. Synthesis was carried out in a $250 \mathrm{~mL}$ three-neck flask equipped with a reflux condenser, inlet and outlet of inert gas and a magnetic stirrer. For 30 min, the mixture was purged with argon, and then the temperature was increased to initiate the polymerization process by thermal decomposition of the initiator (APS). The reaction was carried out under an argon blanket for $6 \mathrm{~h}$, and the stirring rate was set at $250 \mathrm{rpm}$ during the entire polymerization process. After synthesis, the products were dialyzed with $5 \mathrm{~L}$ of water for one week at room temperature, and water was changed daily.

\subsection{Apparatus-HPLC Determination of Bisphenols}

Apparatus for sample preparation was a tube rotator RL-2002 from J.W. Electronic (Warsaw, Poland) and an MPW-55 centrifuge from MPW Medical Instruments (Warsaw, Poland). HPLC analysis was performed on Merck/Hitachi HPLC System (Darmstadt, Germany) equipped with a vacuum degasser, a gradient pump, an autosampler and a fluorescence detector. The data were collected and evaluated by using Merck chromato- 
graphic software D-7000. Chromatographic separation was performed on a reversed-phase SunFire ${ }^{\mathrm{TM}} \mathrm{C} 18$ column $(2.5 \mu \mathrm{m} \times 4.6 \mathrm{~mm} \times 75 \mathrm{~mm})$.

Column temperature was kept at $30{ }^{\circ} \mathrm{C}$, and injection volume was $5 \mu \mathrm{L}$. For all HPLC analyses, an isocratic program $(70 \% \mathrm{~A}, 30 \% \mathrm{~B})$ was used at a flow rate of $1.5 \mathrm{~mL} \cdot \mathrm{min}^{-1}$ by combining solvent A (water with formic acid, $2 \mathrm{mmol}$ ) and solvent $\mathrm{B}$ (acetonitrile). Fluorescence detection was carried out at $230 \mathrm{~nm}$ excitation wavelength and $316 \mathrm{~nm}$ emission wavelength.

The method performance was assessed in terms of linearity, limits of detection and analytical instrumental repeatability. Six-point calibration curves were constructed using standard mixtures of the analytes. Linearity testing indicated a linear response for the method for the concentration range from 0.001 to $1 \mathrm{mg} \cdot \mathrm{L}^{-1}$ with an $\mathrm{R}^{2}$ value 0.9996 for $\mathrm{BPF}$, $R^{2}$ value 0.9994 for BPE, $R^{2}$ value 0.9992 for BPA and $R^{2}$ value 0.9969 for BPB, respectively. The limits of detection achieved for the LC-FLD method were determined to be $5 \mu \mathrm{g} \cdot \mathrm{L}^{-1}$ for BPF, $12 \mu \mathrm{g} \cdot \mathrm{L}^{-1}$ for BPE, $4 \mu \mathrm{g} \cdot \mathrm{L}^{-1} \mathrm{BPA}$ and $15 \mu \mathrm{g} \cdot \mathrm{L}^{-1}$ for $\mathrm{BPB}$, respectively. Repeatability was determined as the RSD of three consecutive injections of the same sample.

\subsection{Solid-Phase Extraction Procedure}

In order to apply our microgel for the preconcentration of bisphenols and calculate the recoveries, we needed to achieve complete sorption of all investigated bisphenols. To optimize the SPE method, the influence of microgel dosages (1, 2.5 and $5 \mathrm{mg}$ ) and the effect of the concentration of BPA $\left(0.01-1 \mathrm{mg} \cdot \mathrm{L}^{-1}\right)$ were investigated. After applying the microgel into microcentrifuge tubes containing $1 \mathrm{~mL}$ of the standard aqueous solution of bisphenols, the mixtures were shaken continually in a tube rotator at $20{ }^{\circ} \mathrm{C}$ for $30 \mathrm{~min}$. After the microgel was separated by centrifugation ( $2 \mathrm{~min}, 14,000 \mathrm{rpm}$ ), the concentration of bisphenols in the supernatant was determined by the LC-FLD method.

The desorption of bisphenols from the microgel matrix was investigated by testing various elution solvents needed for the complete elution of all the analytes from the microgel sorbent. Different compositions of methanol/water mixtures were tested for the evaluation of clean-up efficiency. After each sorption ( $5 \mathrm{mg}$ of microgel, $50 \mu \mathrm{g} \cdot \mathrm{L}^{-1} \mathrm{of}$ a standard mixture of four bisphenols) the microgel was washed with deionized water to check the retention of bisphenols and the next step was eluting bisphenols with the appropriate organic solvent.

\subsection{Analysis of Food Samples}

Food samples were taken from local markets in Warsaw, Poland. The analyzed samples included the liquid part of food and drinks: coated cans (mandarin, peach, two cans of pineapple, mushroom, figs, fruits in syrup and energy drink); polycarbonate bottle (mineral water); plastic packages marked with 7 recycle codes (pickles and sour cabbage); and tap water. The liquid part of each sample was filtered $(0.45 \mu \mathrm{m})$, the $\mathrm{pH}$ was measured and then the liquid was kept at $4{ }^{\circ} \mathrm{C}$ before extraction. All the food samples were measured in their own $\mathrm{pH}$ (Table 1). The $\mathrm{pH}$ of the samples was not adjusted, as our microgel showed stability in the sorption of all bisphenol under $\mathrm{pH} 9$ [28]. For each extraction, $1 \mathrm{~mL}$ of sample was used, and five milligrams of microgel was added. The extraction procedure was made on liquid food samples and liquid food samples spiked with a standard mixture of four bisphenols $\left(50 \mu \mathrm{g} \cdot \mathrm{L}^{-1}\right)$. All mixtures were then shaken in a tube rotator at $20{ }^{\circ} \mathrm{C}$ for $30 \mathrm{~min}$. After separation from the mixtures, the microgel sorbent was washed with $500 \mu \mathrm{L}$ of distilled water, and then bisphenols were eluted with $200 \mu \mathrm{L}$ of $80 \%$ methanol and water solution. Afterwards, all collected samples (the effluent, water after washing and elution solvent after preconcentration) were analyzed by LC-FLD. The recovery $(R)$ was calculated with the following equation:

$$
R=\frac{C_{\text {exp }}}{C_{\text {theor }}} \cdot 100 \%
$$


where $C_{\exp }$ is the experimental concentration of bisphenols after preconcentration, and $C_{\text {theor }}$ is the theoretical concentration, which should be obtained. Extraction repeatability was calculated as the standard deviation (SD) of three replicates.

Table 1. Recoveries of BPF, BPE, BPA and BPB in different liquid food samples spiked with $50 \mu \mathrm{g} \cdot \mathrm{L}^{-1}$ of a standard mixture of four bisphenols using microgel as a sorbent for preconcentration. Data are means with $\operatorname{RSD}(n=3)$.

\begin{tabular}{ccccccc}
\hline \multirow{2}{*}{ Sample } & \multirow{2}{*}{ Packaging Type } & pH of the & BPF & \multicolumn{2}{c}{ BPE } & \multicolumn{2}{c}{ BPA } & BPB \\
\cline { 5 - 7 } & & Sample & & \multicolumn{2}{c}{ Recovery [\%] \pm RSD } \\
\hline Tap water & - & 6.9 & $75.2 \pm 1.76$ & $84.6 \pm 0.66$ & $106 \pm 0.91$ & $109 \pm 2.06$ \\
\hline Mineral water & Polycarbonatebottle & 5.2 & $81.0 \pm 2.34$ & $86.8 \pm 4.34$ & $85.8 \pm 3.21$ & $90.9 \pm 4.54$ \\
\hline Sour cabbage & Package no 7 & 3.4 & $77.1 \pm 5.01$ & $88.5 \pm 0.83$ & $90.0 \pm 1.11$ & $102 \pm 0.21$ \\
\hline Energy drink & Can & 3.5 & $80.9 \pm 1.23$ & $75.2 \pm 4.36$ & $73.2 \pm 3.74$ & $95.4 \pm 4.22$ \\
\hline Pineapple & Can & 3.6 & $75.4 \pm 3.09$ & $84.9 \pm 3.41$ & $109 \pm 0.76$ & $104 \pm 1.17$ \\
\hline Figs & Can & 3.7 & $70.5 \pm 0.54$ & $77.5 \pm 0.95$ & $101 \pm 1.48$ & $83.8 \pm 1.66$ \\
\hline Fruits in syrup & Can & 3.8 & $71.2 \pm 1.71$ & $72.4 \pm 1.22$ & $101 \pm 1.91$ & $108 \pm 1.54$ \\
\hline
\end{tabular}

\subsection{Comparison of Microgel with Commercial SPE Cartridges}

Two different commercial SPE cartridges-Supelclean ${ }^{\mathrm{TM}}$ ENVI-18 (500 mg) and Affinimip ${ }^{\circledR}$ (100 mg) -were chosen to compare their sorption performance with the synthesized microgel. The ENVI-18 cartridge has a polymerically bonded octadecyl sorbent, which is dedicated for extracting and concentrating pollutants from aqueous environmental samples. The Affinimip ${ }^{\circledR}$ cartridge has a molecularly imprinted polymer sorbent that is dedicated for the extraction of bisphenol A or closely related structures and has been already used for bisphenols preconcentration from food samples $[29,30]$.

\section{Results}

\subsection{Characterization of Microgel Sorbent}

Polymer particles were characterized by transmission (TEM) and scanning electron microscopy (SEM) measurements and, in the dried state, they had regular spherical morphology, with an average particle diameter of approximately $100 \mathrm{~nm}$. The influence of various parameters affecting the sorption of bisphenols on the microgel sorbent $(\mathrm{pH}$, contact time, temperature and adsorption isotherm) was investigated and carefully discussed in the previous paper [28]. The results showed that the temperature and $\mathrm{pH}$ of the sample did not affect the sorption in a rather wide range $\left(20-60{ }^{\circ} \mathrm{C}\right)$ and had a $\mathrm{pH}$ lower than 9. An analysis of experimental sorption data indicated that the sorption of bisphenols was characterized by a pseudo-second-order kinetic model and the data fitted well the Langmuir adsorption model. The maximum adsorption capacity obtained for bisphenols was in the range from $55 \mathrm{mg} \cdot \mathrm{g}^{-1}$ for BPF to $160 \mathrm{mg} \cdot \mathrm{g}^{-1}$ for BPB. The microgel was stable for up to five adsorption recycles without an obvious decrease in removal efficiency. What is more is that the possible generation of secondary pollutants, which may leach from the microgel, was also monitored by using LC-FLD [28].

\subsection{Effect of the Amount of Microgel}

In order to achieve the maximum quantitative recovery in the extraction of bisphenols, different amounts of microgel were tested. Therefore, 1, 2.5 and $5 \mathrm{mg}$ of microgel were applied for the sorption of different concentrations of BPA. Figure 2 illustrates that the more microgel sorbent was applied, the higher concentration of BPA was adsorbed. Although our poly $\left(\mathrm{MEO}_{2} \mathrm{MA}\right)$ microgel had a large adsorption capacity $\left(\mathrm{Q}_{\max }\right.$ in the range of 55 to $159 \mathrm{mg} \cdot \mathrm{g}^{-1}$ for all tested bisphenols [28]), $1 \mathrm{mg}$ of microgel was not sufficient for the total sorption of even the smallest concentration of BPA. The amount of $5 \mathrm{mg}$ of the microgel 
provided the best sorption of BPA, which remained above $95 \%$ in the range from 0.025 to $1 \mathrm{mg} \cdot \mathrm{L}^{-1}$, while for $2.5 \mathrm{mg}$ the sorption for the concentration higher than $0.025 \mathrm{mg} \cdot \mathrm{L}^{-1}$ gradually decreased to $90 \%$. As our goal was to use the microgel for the sorption of several bisphenols, $5 \mathrm{mg}$ of microgel sorbent was selected for further experiments.

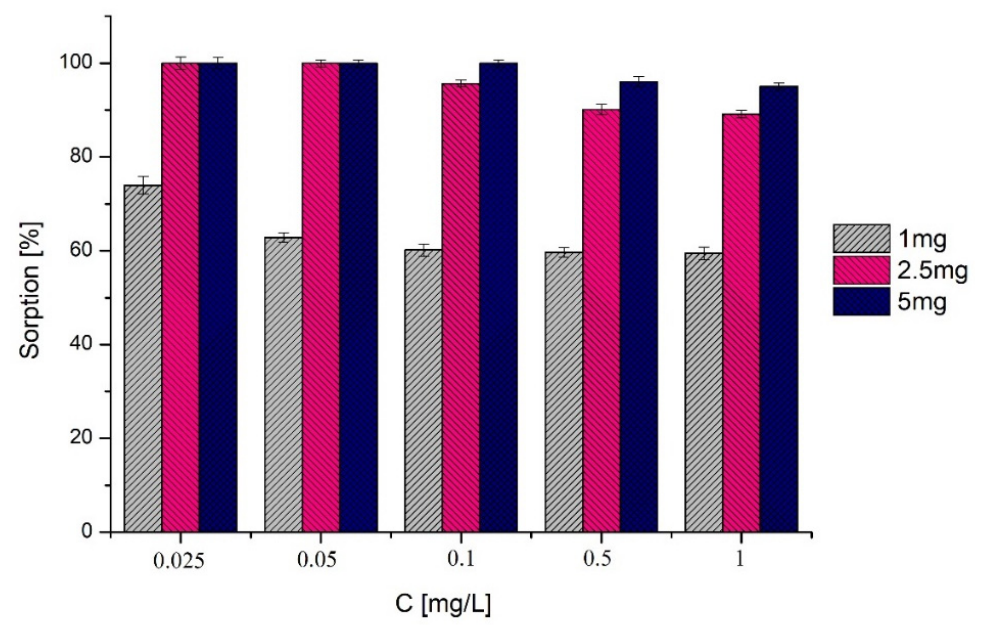

Figure 2. The effect of the initial concentration of BPA $\left(0.025-1 \mathrm{mg} \cdot \mathrm{L}^{-1}\right)$ and the amount of microgel on the sorption. Data are means with $\operatorname{RSD}(n=3)$.

\subsection{Desorption}

The elution solvent must be capable of disrupting all retentive interactions between the analyte and sorbent but not too strong as to remove tightly bound contaminants. One milliliter of pure methanol was sufficient to obtain a complete desorption for all the analyzed bisphenols, which were adsorbed on the microgel. However, when $100 \%$ organic solvent is injected into liquid chromatography, the peaks for analytes become broad and asymmetric; this is why the different compositions of methanol and water were also studied for bisphenols removal. In order to obtain a 5-fold preconcentration of $1 \mathrm{~mL}$ of the sample, $200 \mu \mathrm{L}$ of each methanol/water mixture was tested for the elution of all bisphenols. As presented in Figure 3, $80 \%$ of $\mathrm{MeOH}(80 / 20$ methanol and deionized water) obtained the best desorption efficiency for all four bisphenols. This is why it was selected as the optimum elution solvent for further extraction studies.

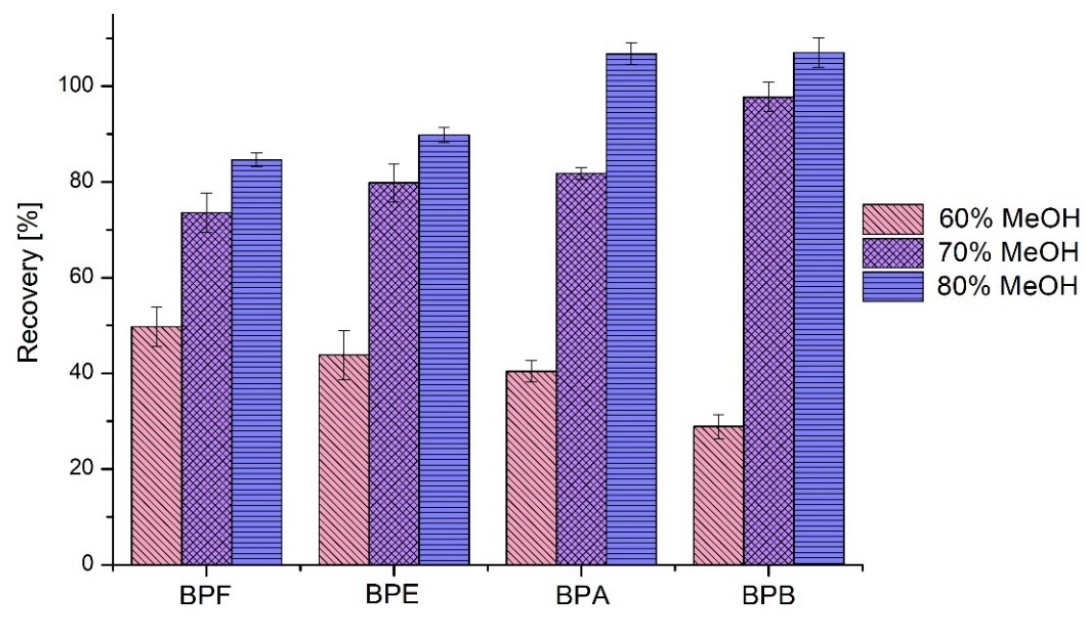

Figure 3. The recovery obtained for a 5-time preconcentration of $50 \mu \mathrm{g} \cdot \mathrm{L}^{-1}$ mixture of four bisphenols with each of the elution mixture (different ratio of methanol and water). Data are means with RSD $(n=3)$. 


\subsection{Extraction of Bisphenols from Food Samples}

Based on the above results, poly $\left(\mathrm{MEO}_{2} \mathrm{MA}\right)$ microgel was employed as a sorbent for selective extraction of BPF, BPE, BPA and BPB from liquid food samples. Preliminary research with sample preparation of solid parts of food was performed with liquid organic solvents. When organic extracts were applied directly into microgel, it resulted in very poor retention of bisphenols. On the other hand, the evaporation of the organic solvents caused some loss of bisphenols. For that reason, only liquid samples were chosen for further studies.

As listed in Table 1, very good recoveries with the relative standard deviations (RSD) of $0.21-5.01 \%$ were obtained for all liquid food samples spiked with $50 \mu \mathrm{g} \cdot \mathrm{L}^{-1}$ mixture of bisphenols. Slightly poorer recoveries (70.5-84.9\%) were obtained for BPF and BPE in fruit canned samples, which were caused by the weaker retention of these bisphenols, as around $10 \%$ of the spiked concentration of BPF and BPE were found in the effluent of each spiked food sample. Due to the relatively high complexity of food samples such as those tested, in some cases, the peaks from bisphenols were overlapped by the peak from the matrix, which made it impossible to assess recovery; this happened for the determination of BPB in mushroom or peach sample.

In five of the analyzed samples (pineapple, peach, mandarin, mushroom and pickles), the recovery for BPA was significantly higher than $110 \%$, which resulted in the conclusion that they might be contaminated with BPA. Further experiments with the preconcentration of food extracts (without spiking) confirmed our suspicions. Figure 4 presents the LC-FLD chromatograms of the following: (A) liquid pineapple sample after the microgel preconcentration (visible peak for $B P A, t_{R}=6.39 \mathrm{~min}$ ); $(B)$ is the chromatogram of the liquid pineapple sample before the preconcentration procedure; and $(\mathrm{C})$ presents the chromatogram of liquid pineapple sample spiked with $0.5 \mathrm{mg} \cdot \mathrm{L}^{-1}$ of four analyzed bisphenols, where the retention times were as follows: $3.03 \mathrm{~min}(\mathrm{BPF}), 4.39 \mathrm{~min}$ (BPE), $6.36 \mathrm{~min}(\mathrm{BPA})$ and $11.2 \mathrm{~min}(\mathrm{BPB})$. After the extraction procedure, the detected and calculated concentration of bisphenol $\mathrm{A}$ was $6.2 \mu \mathrm{g} \cdot \mathrm{L}^{-1}$ for pineapple, $8.5 \mu \mathrm{g} \cdot \mathrm{L}^{-1}$ for mandarin, $11 \mu \mathrm{g} \cdot \mathrm{L}^{-1}$ for mushroom, $12 \mu \mathrm{g} \cdot \mathrm{L}^{-1}$ for pickles and $22 \mu \mathrm{g} \cdot \mathrm{L}^{-1}$ for peach (Table 2 ). These results are below the migration limits set for BPA $\left(50 \mu \mathrm{g} \cdot \mathrm{kg}^{-1}\right)$ [31].

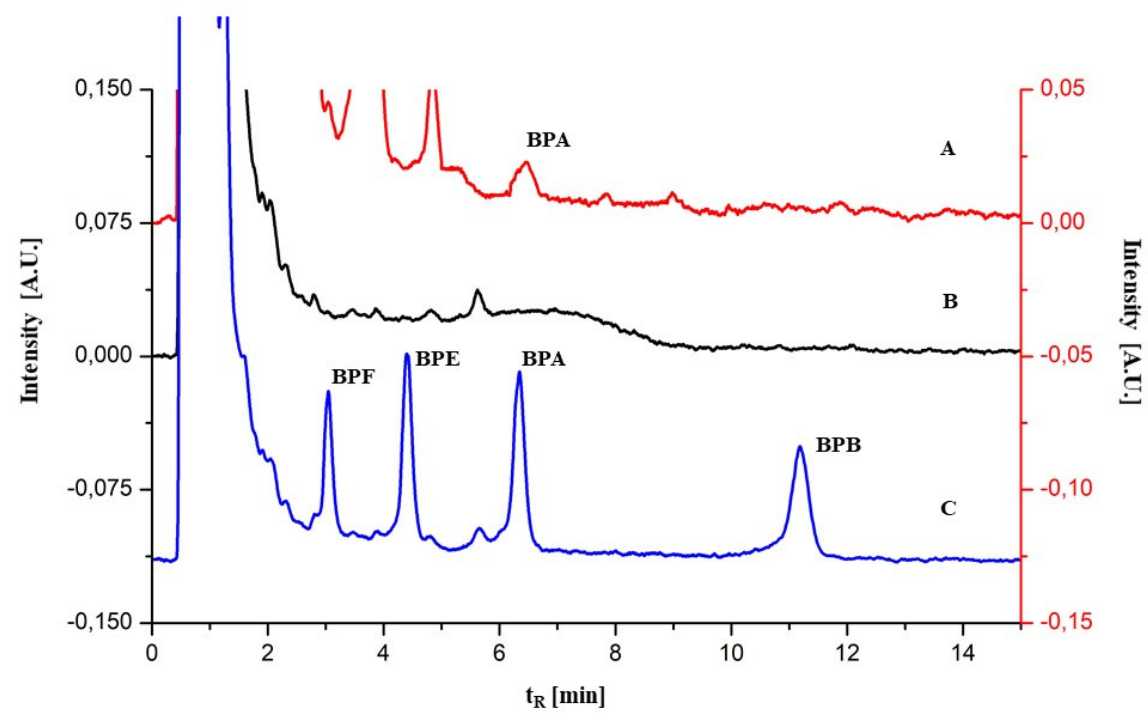

Figure 4. LC-FLD chromatograms of (A) liquid pineapple sample after microgel preconcentration (with the visible peak for BPA, $t_{R}=6.39 \mathrm{~min}$ ), (B) liquid pineapple sample before preconcentration procedure and $(C)$ liquid pineapple spiked with the standard solution of bisphenols $\left(0.5 \mathrm{mg} \cdot \mathrm{L}^{-1}\right)$. 
Table 2. The detected concentration of bisphenol A in liquid food samples after the extraction procedure.

\begin{tabular}{cccccc}
\hline \multirow{2}{*}{ Analyte } & Pineapple & Mandarin & Mushroom & Peach & Pickles \\
\cline { 2 - 5 } & \multicolumn{5}{c}{$\mathrm{C}\left[\boldsymbol{\mu} \cdot \mathbf{L}^{-\mathbf{1}}\right]$} \\
\hline BPA & $6.2 \pm 0.9$ & $8.5 \pm 0.4$ & $11 \pm 0.4$ & $22 \pm 2.0$ & $12 \pm 1.2$ \\
\hline
\end{tabular}

\subsection{Comparison of Microgel with SPE Cartridges}

Both SPE procedures for Supelclean ${ }^{\mathrm{TM}}$ ENVI-18 and Affinimip ${ }^{\circledR}$ cartridges were taken from the producer's application notes with slight modifications (Table 3). The suggested cleaning mixture has a higher concentration of organic solvent, which throughout the extraction procedure resulted in eluting bisphenols from the sorbent of both cartridges. This is why the cleaning mixture was changed to $5 / 95 \mathrm{ACN} / \mathrm{H}_{2} \mathrm{O}$. The amount of $10 \mathrm{~mL}$ of filtered extract from fruits in syrup (without dilution) was spiked with $50 \mu \mathrm{g} \cdot \mathrm{L}^{-1}$ standard solution of $\mathrm{BPB}, \mathrm{BPE}, \mathrm{BPF}$ and $\mathrm{BPA}$, and then it was introduced into the SPE cartridge. Following the application of the extract, cartridges were washed with $5 \mathrm{~mL}$ of $5 / 95$ acetonitrile/water mixture, and each sample was eluted with $2 \mathrm{~mL}$ of $80 \%$ of methanol/water mixture. The experiments for microgel were performed in $2 \mathrm{~mL}$ microcentrifuge tubes; for that reason, the amount of the loading sample and elution solvent must be smaller in comparison to SPE cartridges. After preconcentration, all collected samples were analyzed by LC-FLD, and recoveries were calculated.

Table 3. Solid-phase extraction methods used for preconcentration of fruits in syrup.

\begin{tabular}{|c|c|c|c|}
\hline Sorbent & Microgel (5 mg) & ENVI-18 (500 mg) & Affinimip $^{\circledR}$ (100 mg) \\
\hline Conditioning & - & $\begin{array}{c}5 \mathrm{~mL} \text { of } \mathrm{MeOH}^{1} \\
5 \mathrm{~mL} \text { of } \mathrm{H}_{2} \mathrm{O}\end{array}$ & $\begin{array}{c}3 \mathrm{~mL} \text { of } 2 \% \mathrm{FA}^{2} / \mathrm{MeOH} \\
3 \mathrm{~mL} \mathrm{ACN}^{3} \\
3 \mathrm{~mL} \mathrm{H}_{2} \mathrm{O}\end{array}$ \\
\hline Loading & $\begin{array}{l}1 \mathrm{~mL} \text { of fruits in syrup } \\
\text { spiked with } 50 \mu \mathrm{g} \cdot \mathrm{L}^{-1}\end{array}$ & $\begin{array}{l}10 \mathrm{~mL} \text { of fruits in syrup } \\
\text { spiked with } 50 \mu \mathrm{g} \cdot \mathrm{L}^{-1}\end{array}$ & $\begin{array}{l}10 \mathrm{~mL} \text { of fruits in syrup } \\
\text { spiked with } 50 \mu \mathrm{g} \cdot \mathrm{L}^{-1}\end{array}$ \\
\hline Cleaning & $0.5 \mathrm{~mL}$ of $\mathrm{H}_{2} \mathrm{O}$ & $5 \mathrm{~mL}$ of $5 / 95 \mathrm{ACN} / \mathrm{H}_{2} \mathrm{O}$ & $5 \mathrm{~mL}$ of $5 / 95 \mathrm{ACN} / \mathrm{H}_{2} \mathrm{O}$ \\
\hline Elution & $0.2 \mathrm{~mL}$ of $80 \% \mathrm{MeOH}$ & $2 \mathrm{~mL}$ of $80 \% \mathrm{MeOH}$ & $2 \mathrm{~mL}$ of $80 \% \mathrm{MeOH}$ \\
\hline
\end{tabular}

As presented in Figure 5, both cartridges showed very good recoveries (101.3-115.6\% for Affinimip ${ }^{\circledR}$ and $98.5-112.8 \%$ for Supelclean ${ }^{\mathrm{TM}}$ ENVI-18) for preconcentration of $10 \mathrm{~mL}$ of fruits in syrup spiked with $50 \mu \mathrm{g} \cdot \mathrm{L}^{-1}$ standard solution of investigated bisphenols. However, the Supelclean ${ }^{\mathrm{TM}}$ ENVI-18 cartridge was easily clogged with the matrix of the food sample, which prolonged the SPE procedure. The recoveries obtained for our microgel SPE procedure were comparable (from 71.2 to $108.3 \%$ for all bisphenols). However, lower recoveries (71.2-72.4\%) obtained for BPE and BPF were caused by weaker retention of both bisphenols on microgel as small amounts were found in the effluent. In order to verify the results obtained on the microgel, all the samples where BPA was found (mandarin, pineapple, mushroom, peach and pickles) were also preconcentrated by using Affinimip ${ }^{\circledR}$ cartridge, and the results were consistent with each other. For example, by using Affinimip ${ }^{\circledR}$ cartridge for preconcentration, the determined amount of BPA in pickles was $10.9 \mu \mathrm{g} \cdot \mathrm{L}^{-1}$ and $19.8 \mu \mathrm{g} \cdot \mathrm{L}^{-1}$ for peach. These results differ only by less than $10 \%$ to the concentrations determined after microgel extraction (Table 2). 


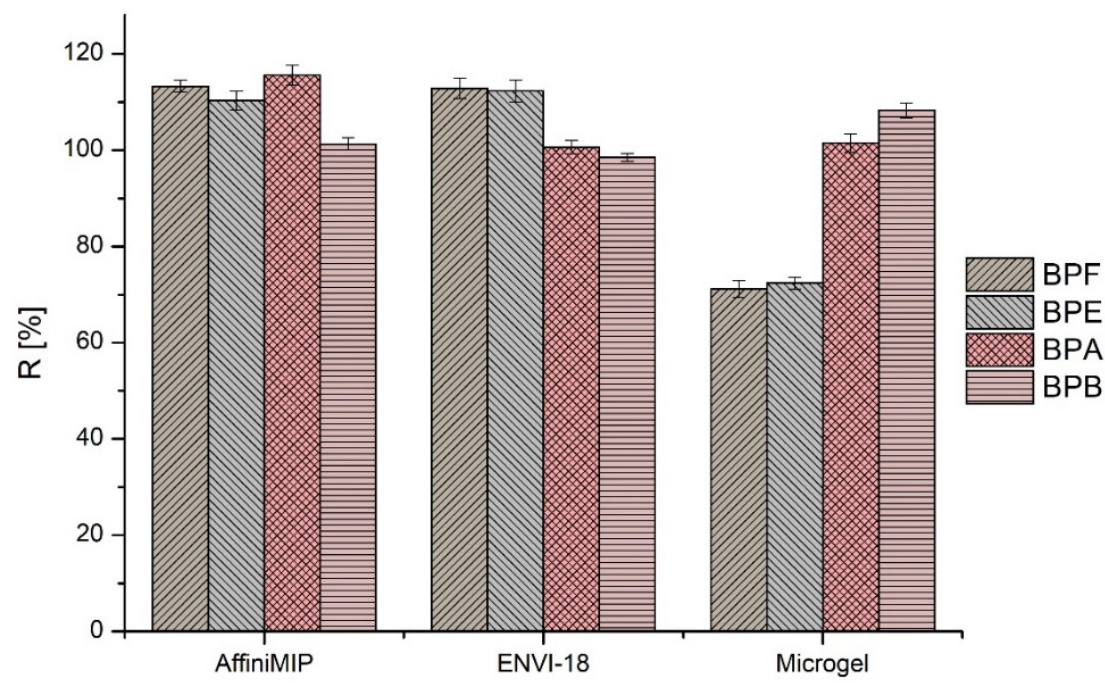

Figure 5. Comparison of our microgel performance with commercial SPE cartridges. Results obtained for fruits in syrup spiked with $50 \mu \mathrm{g} \cdot \mathrm{L}^{-1}$ mixture of four bisphenols. Data are means with RSD $(n=3)$.

\section{Discussion}

For the very first time, the microgel was used as a sorbent in the preconcentration of bisphenols from complicated liquid matrices. The optimized microgel-SPE procedure with further analysis with LC-FLD allowed for 5 -fold preconcentration of food samples and obtaining an LOD down to $0.9 \mathrm{ng} \cdot \mathrm{mL}^{-1}$ for BPF and BPA, $2.3 \mathrm{ng} \cdot \mathrm{mL}^{-1}$ for BPE and $2.9 \mathrm{ng} \cdot \mathrm{mL}^{-1}$ for BPB. The high extraction efficiency of microgel for different complex matrices suggests that the developed poly $\left(\mathrm{MEO}_{2} \mathrm{MA}\right)$ microgel might be the effective solution for sample preparation in routine analysis of trace BPF, BPE, BPA and BPB. The application of microgel as sorbent resulted in discovering trace concentrations of BPA in five out of the twelve of the analyzed liquid food samples (mandarin, pineapple, peach, pickles and mushroom). The results of the cleanup and the obtained recoveries are comparable to commercial cartridges. Moreover, compared to different methods reported in the literature (listed in Table 4) the obtained limit of detection for BPF and BPA was lower than others who used classical liquid chromatography.

Table 4. Comparison of our method of preconcentration of bisphenols to others.

\begin{tabular}{|c|c|c|c|c|c|}
\hline Analyte(s) & Sample & $\begin{array}{c}\text { Sample } \\
\text { Preparation }\end{array}$ & Determination & $\begin{array}{c}\text { LOD } \\
{\left[\mu \mathrm{g} \cdot \mathrm{L}^{-1}\right]}\end{array}$ & Ref. \\
\hline BPF, BPA & honey & MIP & LC-DAD & BPF, BPA 2.0 & [32] \\
\hline $\mathrm{BPB}, \mathrm{BPA}$ & $\begin{array}{l}\text { peeled canned } \\
\text { tomatoes }\end{array}$ & $\begin{array}{c}\text { (I). Strata C18 } \\
\text { (II). Florisil SPE } \\
\text { cartridges }\end{array}$ & LC-UV/FLD & $\begin{array}{l}\text { BPB } 0.7 \\
\text { BPA } 1.1\end{array}$ & [33] \\
\hline $\mathrm{BPB}, \mathrm{BPA}$ & tuna & LLE & LC-FLD & $\begin{array}{l}\text { BPA } 1.3 \\
\text { BPB } 3.0\end{array}$ & [34] \\
\hline $\begin{array}{l}\text { BPB, BPE } \\
\text { BPF, BPA } \\
\quad \text { BPS }\end{array}$ & $\begin{array}{l}\text { plastic packed baby } \\
\text { food }\end{array}$ & $\begin{array}{c}\text { (I). LLE } \\
\text { (II). C18 and PSA } \\
\text { SPE cartridges }\end{array}$ & GC-MS/MS & $\begin{array}{c}\text { BPF } 0.1 \\
\text { BPB, BPE, BPA, } \\
\text { BPS } 0.3\end{array}$ & [12] \\
\hline BPF, BPA, BPB & $\begin{array}{l}\text { canned } \\
\text { energy } \\
\text { drinks }\end{array}$ & $\begin{array}{l}\text { Affinimip }{ }^{\circledR} \\
\text { cartridge }\end{array}$ & UHPLC-FLD & BPB, BPF, BPA 0.2 & [29] \\
\hline $\begin{array}{l}\mathrm{BPF}, \mathrm{BPE}, \mathrm{BPA}, \\
\text { BPB }\end{array}$ & $\begin{array}{l}\text { energy drink, liquid } \\
\text { from can (pineapple, } \\
\text { mandarin, figs) }\end{array}$ & Microgel & LC-FLD & $\begin{array}{c}\text { BPF, BPA } 0.9 \\
\text { BPE } 2.3 \\
\text { BPB } 2.9\end{array}$ & This work \\
\hline
\end{tabular}


It should be noted that the consideration of analyzing bisphenols from a quality assurance perspective require quantitation of bisphenols in both solid and liquid parts of food products. This was also confirmed in the work of Tzatzarakis et al. [35], where higher amounts of bisphenol A were found in solid parts than liquid part of canned food. This is why further studies are necessary for optimizing bisphenols extraction procedure from solid parts of food. On the other hand, considering all the above benefits, the authors hope that this study would be beneficial for the further development and application of microgel sorbents.

Author Contributions: Conceptualization, investigation, validation and writing-original draft preparation, A.K.; formal analysis and synthesis, M.M.; writing-review and editing, M.K. and M.B.; supervision, M.B. All authors have read and agreed to the published version of the manuscript.

Funding: This work was supported by the National Science Centre, Poland, under grant number 2018/31/B/ST5/02859.

Institutional Review Board Statement: Not applicable.

Data Availability Statement: Not applicable.

Conflicts of Interest: The authors declare that they have no known competing financial interests or personal relationships that could have appeared to influence the work reported in this paper. The funders had no role in the design of the study; in the collection, analyses, or interpretation of data; in the writing of the manuscript; or in the decision to publish the results.

\section{References}

1. González, N.; Cunha, S.C.; Ferreira, R.; Fernandes, J.O.; Marquès, M.; Nadal, M.; Domingo, J.L. Concentrations of nine bisphenol analogues in food purchased from Catalonia (Spain): Comparison of canned and non-canned foodstuffs. Food Chem. Toxicol. 2020, 136, 110992. [CrossRef]

2. Munguia-Lopez, E.M.; Peralta, E.; Gonzalez-Leon, A.; Vargas-Requena, C.; Soto-Valdez, H. Migration of bisphenol A (BPA) from epoxy can coatings to jalapeño peppers and an acid food simulant. J. Agric. Food Chem. 2002, 50, 7299-7302. [CrossRef]

3. Pedersen, G.A.; Hvilste, S.; Petersen, J.H. Migration of Bisphenol A from Polycarbonate Plastic of Different Qualities; Environmental Project No. 1710; Danish Ministry of the Environment: Copenhagen, Denmark, 2015.

4. Schug, T.T.; Birnbaum, L.S. Toxicants in Food Packaging and Household Plastics; Snedeker, S.M., Ed.; Springer: London, UK, 2014; pp. 1-29. [CrossRef]

5. Cuvillier-Hot, V.; Lenoir, A. Invertebrates facing environmental contamination by endocrine disruptors: Novel evidences and recent insights. Mol. Cell. Endocrinol. 2020, 504, 110712. [CrossRef] [PubMed]

6. Donato, M. Di; Cernera, G.; Giovannelli, P.; Galasso, G.; Bilancio, A.; Migliaccio, A.; Castoria, G.; Di Donato, M. Recent advances on bisphenol-A and endocrine disruptor effects on human prostate cancer. Mol. Cell. Endocrinol. 2017, 457, 35-42. [CrossRef] [PubMed]

7. Rezg, R.; El-Fazaa, S.; Gharbi, N.; Mornagui, B. Bisphenol A and human chronic diseases: Current evidences, possible mechanisms, and future perspectives. Environ. Int. 2014, 64, 83-90. [CrossRef] [PubMed]

8. Zhang, Y.F.; Shan, C.; Wang, Y.; Qian, L.L.; Jia, D.D.; Zhang, Y.F.; Hao, X.D.; Xu, H.M. Cardiovascular toxicity and mechanism of bisphenol A and emerging risk of bisphenol S. Sci. Total Environ. 2020, 723, 137952. [CrossRef] [PubMed]

9. Ma, Y.; Liu, H.; Wu, J.; Yuan, L.; Wang, Y.; Du, X.; Wang, R.; Marwa, P.W.; Petlulu, P.; Chen, X.; et al. The adverse health effects of bisphenol A and related toxicity mechanisms. Environ. Res. 2019, 176, 108575. [CrossRef] [PubMed]

10. Bhatnagar, A.; Anastopoulos, I. Chemosphere Adsorptive removal of bisphenol A (BPA) from aqueous solution: A review. Chemosphere 2017, 168, 885-902. [CrossRef]

11. Sun, X.; Wang, J.; Li, Y.; Jin, J.; Zhang, B.; Shah, S.M.; Wang, X.; Chen, J. Highly selective dummy molecularly imprinted polymer as a solid-phase extraction sorbent for five bisphenols in tap and river water. J. Chromatogr. A 2014, 1343, 33-41. [CrossRef] [PubMed]

12. García-Córcoles, M.T.; Cipa, M.; Rodríguez-Gómez, R.; Rivas, A.; Olea-Serrano, F.; Vílchez, J.L.; Zafra-Gómez, A. Determination of bisphenols with estrogenic activity in plastic packaged baby food samples using solid-liquid extraction and clean-up with dispersive sorbents followed by gas chromatography tandem mass spectrometry analysis. Talanta 2018, 178, 441-448. [CrossRef]

13. Usman, A.; Ikhlas, S.; Ahmad, M. Occurrence, toxicity and endocrine disrupting potential of Bisphenol-B and Bisphenol-F: A mini-review. Toxicol. Lett. 2019, 312, 222-227. [CrossRef]

14. Qiu, W.; Zhan, H.; Hu, J.; Zhang, T.; Xu, H.; Wong, M.; Xu, B.; Zheng, C. The occurrence, potential toxicity, and toxicity mechanism of bisphenol S, a substitute of bisphenol A: A critical review of recent progress. Ecotoxicol. Environ. Saf. 2019, 173, 192-202. [CrossRef]

15. Chen, D.; Kannan, K.; Tan, H.; Zheng, Z.; Feng, Y.L.; Wu, Y.; Widelka, M. Bisphenol Analogues Other Than BPA: Environmental Occurrence, Human Exposure, and Toxicity-A Review. Environ. Sci. Technol. 2016, 50, 5438-5453. [CrossRef] 
16. Rochester, J.R.; Bolden, A.L. Bisphenol S and F: A systematic review and comparison of the hormonal activity of bisphenol a substitutes. Environ. Health Perspect. 2015, 123, 643-650. [CrossRef]

17. Ballesteros-Gómez, A.; Rubio, S.; Pérez-Bendito, D. Analytical methods for the determination of bisphenol A in food. J. Chromatogr. A 2009, 1216, 449-469. [CrossRef] [PubMed]

18. Kubiak, A.; Biesaga, M. Application of Molecularly Imprinted Polymers for Bisphenols Extraction from Food Samples-A Review. Crit. Rev. Anal. Chem. 2020, 50, 311-321. [CrossRef]

19. Sun, F.; Kang, L.; Xiang, X.; Li, H.; Luo, X.; Luo, R.; Lu, C.; Peng, X. Recent advances and progress in the detection of bisphenol A. Anal. Bioanal. Chem. 2016, 408, 6913-6927. [CrossRef] [PubMed]

20. Caballero-Casero, N.; Lunar, L.; Rubio, S. Analytical methods for the determination of mixtures of bisphenols and derivatives in human and environmental exposure sources and biological fluids. A review. Anal. Chim. Acta 2016, 908, 22-53. [CrossRef] [PubMed]

21. Zhu, R.; Zhao, W.; Zhai, M.; Wei, F.; Cai, Z.; Sheng, N.; Hu, Q. Molecularly imprinted layer-coated silica nanoparticles for selective solid-phase extraction of bisphenol A from chemical cleansing and cosmetics samples. Anal. Chim. Acta 2010, 658, 209-216. [CrossRef]

22. Salgueiro-Gonz Alez, N.; Castiglioni, S.; Zuccato, E.; Turnes-Carou, I.; Opez-Mahía, P.L.; Muniategui-Lorenzo, S.; Acta, A.C. Recent advances in analytical methods for the determination of 4-alkylphenols and bisphenol A in solid environmental matrices: A critical review. Anal. Chim. Acta 2018, 1024, 39-51. [CrossRef]

23. Salehinia, S.; Ghoreishi, S.M.; Maya, F.; Cerdà, V. Hydrophobic magnetic montmorillonite composite material for the efficient adsorption and microextraction of bisphenol A from water samples. J. Environ. Chem. Eng. 2016, 4, 4062-4071. [CrossRef]

24. Zhou, A.; Wu, X.; Chen, W.; Liao, L.; Xie, P. Fabrication of hydrophobic/hydrophilic bifunctional adsorbent for the removal of sulfamethoxazole and bisphenol A in Water. J. Environ. Chem. Eng. 2020, 8, 104161. [CrossRef]

25. Hou, N.; Wang, R.; Geng, R.; Wang, F.; Jiao, T.; Zhang, L.; Zhou, J.; Bai, Z.; Peng, Q. Facile preparation of self-assembled hydrogels constructed from poly-cyclodextrin and poly-adamantane as highly selective adsorbents for wastewater treatment. Soft Matter 2019, 15, 6097-6106. [CrossRef]

26. Naseem, K.; Hussain Farooqi, Z.; Zia Ur Rehman, M.; Atiq Ur Rehman, M.; Ghufran, M. Microgels as efficient adsorbents for the removal of pollutants from aqueous medium. Rev. Chem. Eng. 2019, 35, 285-309. [CrossRef]

27. Du, H.; Piao, M. Facile preparation of microscale hydrogel particles for high efficiency adsorption of bisphenol A from aqueous solution. Environ. Sci. Pollut. Res. 2018, 25, 28562-28571. [CrossRef]

28. Kubiak, A.; Maćkiewicz, M.; Biesaga, M.; Karbarz, M. Highly efficient removal of bisphenols from aqueous solution using environmental-sensitive microgel. J. Environ. Chem. Eng. 2021, 9, 104947. [CrossRef]

29. Gallo, P.; Di Marco Pisciottano, I.; Esposito, F.; Fasano, E.; Scognamiglio, G.; Mita, G.D.; Cirillo, T. Determination of BPA, BPB, $\mathrm{BPF}, \mathrm{BADGE}$ and BFDGE in canned energy drinks by molecularly imprinted polymer cleaning up and UPLC with fluorescence detection. Food Chem. 2017, 220, 406-412. [CrossRef]

30. Alenazi, N.A.; Manthorpe, J.M.; Lai, E.P.C. Selective extraction of BPA in milk analysis by capillary electrophoresis using a chemically modified molecularly imprinted polymer. Food Control 2015, 50, 778-783. [CrossRef]

31. Sungur, S..; Koroğlu, M.; Özkan, A. Determination of bisphenol a migrating from canned food and beverages in markets. Food Chem. 2014, 142, 87-91. [CrossRef]

32. Herrero-Hernández, E.; Carabias-Martínez, R.; Rodríguez-Gonzalo, E. Use of a bisphenol-A imprinted polymer as a selective sorbent for the determination of phenols and phenoxyacids in honey by liquid chromatography with diode array and tandem mass spectrometric detection. Anal. Chim. Acta 2009, 650, 195-201. [CrossRef] [PubMed]

33. Grumetto, L.; Montesano, D.; Seccia, S.; Albrizio, S.; Barbato, F. Determination of Bisphenol A and Bisphenol B Residues in Canned Peeled Tomatoes by Reversed-Phase Liquid Chromatography. J. Agric. Food Chem. 2008, 56, 10633-10637. [CrossRef] [PubMed]

34. Fattore, M.; Russo, G.; Barbato, F.; Grumetto, L.; Albrizio, S. Monitoring of bisphenols in canned tuna from Italian markets. Food Chem. Toxicol. 2015, 83, 68-75. [CrossRef] [PubMed]

35. Tzatzarakis, M.N.; Vasiliki, K.; Vakonaki, E.; Goumenou, M.; Kavvalakis, M.; Stivaktakis, P.; Tsitsimpikou, C.; Tsakiris, I.; Rizos, A.; Tsatsakis, A.M. Bisphenol A in Soft Drinks and Canned Foods and Data Evaluation. Food Addit. Contam. Part B 2017, 10, 85-90. [CrossRef] [PubMed] 